\title{
When Hosts Disclose Their Private Information on Accommodation Sharing Platforms: An Information Commercialization Perspective
}

\author{
Jiang $\mathrm{Hu}$ \\ University of Texas at Arlington \\ jiang.hu@mavs.uta.edu
}

\author{
Wei He \\ Texas Tech University \\ wei.he@ttu.edu
}

\author{
Fred Davis \\ Texas Tech University \\ fred.davis@ttu.edu
}

\begin{abstract}
The proliferation of the Internet and platform economy has given rise to the sharing economy as a popular business model. While much research has focused on the economic and social benefits aspects, privacy issue in sharing economy is often overlooked. Drawing on the privacy calculus theory and the literature of information-as-a-commodity perspective, this study focuses on accommodation sharing platform Airbnb and aims to investigate the critical role of hosts' information commercialization in leading to their private information disclosure behavior on the platform. This study fills in the research gap by theorizing the concept of information commercialization in accommodation sharing platforms and addressing its formation mechanisms and behavioral outcome.
\end{abstract}

\section{Introduction}

The proliferation of the Internet and platform economy has given rise to the sharing economy as a popular business model. Sharing economy is typically defined as a peer-to-peer-based activity referring to "a set of techniques and practices that facilitate trusted transactions between strangers" through renting, giving, or sharing access to goods or services. Consumers can benefit from sharing economy by purchasing goods or adopting services at a lower cost than buying or renting through a traditional provider (Zervas et al. 2017). According to a recent survey, nearly a quarter $(21.0 \%)$ of US adult Internet users (or 44.8 million people) experienced sharing economy services at least once in 2016 (eMarketer 2017). There are typically three sharing economy models. The first one is Business-toCustomer (B2C), in which firms possess the resources and provide services to individuals, such as Zipcar, Car2Go and Lime. The second type is Customer-toCustomer (C2C). In this model, supplier and demander are individuals, connected by platform like Airbnb,
Uber or HomeExchange. The third sharing economy model is Customer-to-Business (C2B). Enterprises get resources through crowdsourcing or crowdfunding, such as Threadless and 99designs. This study focuses on $\mathrm{C} 2 \mathrm{C}$ type of sharing economy, also known as "collaborative consumption" or peer-to-peer based transactions (Hamari et al. 2016; Calo and Rosenblat 2017), specifically, Airbnb. Airbnb connects individuals who want to rent out their spare rooms in their apartments or entire home with travelers who are looking for accommodations for a short-term stay.

Although more and more people now consider accommodation sharing as their mainstream alternatives, platforms like Airbnb involve privacy concerns for two parties of a transaction, namely, consumers and hosts. While consumers' privacy concerns in using accommodation sharing platforms is similar to the ones in e-commerce context (Awad and Krishnan 2006), hosts releasing private information may represent a unique research question. The uniqueness lies in the following three aspects. First, traditional e-commerce platforms typically collect and store consumers' credit card and address information for payment and delivery, or consumers' preferences, behaviors and locational data for personalization $(\mathrm{Xu}$, Luo, Carroll, and Rosson 2011). However, information published by hosts on accommodation sharing platforms is more personal and sensitive. For example, Airbnb hosts post the information of their occupation, hobby and even information about their family members sometimes.

Second, when consumers share their personal information for exchanging an economic value or better personalization (e.g., Acquisti and Grossklas 2005; Taylor, Davis, and Jillapalli 2009; Xu et al. 2011), the decision is usually based on an immediate or one-off economic consideration and the consumer's information is kept by businesses (e.g., the Ecommerce firms). In this type of context, government legislation and industry self-regulation would act as powerful control agents that safeguard consumers' personal information from being abused such that consumers may have less concern for information 
privacy (Xu, Teo, Tan, and Agarwal 2012). However, hosts on accommodation sharing platforms take more risks of exposing themselves to a vast number of individuals whose integrity and trustworthiness are doubtful. Airbnb hosts post the graphs of inside view of their home on the platform, together with rough geographic information, associated facilities, surrounding attractions, traffic connectivity, etc. Since the assets, such as houses or apartments, are still possessed by the hosts after transactions, disclosure of this type of private information may lead to serious security problems. Hosts may also worry about their physical property being stolen, broken or misused. For instance, an Airbnb host, who works as a photographer, reported to the police that his camera equipment and electronics were missing, together with his social insurance card and a photo ID, although all his valuables had been stored in locked areas (Breen 2017).

Third, on the accommodation sharing platforms, hosts tend to actively look for and verify consumer's information to identify qualified consumer since the products are hosts' self-belongings. Sometimes, hosts only rent out one room in their house and hosts may have offline interaction with the consumers (Lutz et al. 2018). Therefore, not only consumers but also hosts would have concerns on their privacy and personal safety, such as harassment, stalking and discrimination. For instance, an Airbnb host in Dallas reported to the police one of her previous guests kept harassing her through messages and showing up around her apartment since he knew where she lives (Strapagiel 2018). Therefore, hosts want to guarantee the safety of themselves as well as their property during the transaction. In contrast, consumer's identification is not an important factor to seller on traditional ecommerce platform.

Previous studies on privacy concerns have mostly been conducted in the contexts of e-commerce website (e.g., Awad and Krishnan 2006), online health (e.g., Anderson and Agarwal 2011), and social networking sites (e.g., Krasnova et al. 2010; Zhao et al. 2012). A majority of these studies have drawn upon the privacy calculus theory or similar theories (e.g., utility theory) to understand why consumers would be willing to disclose their information online, basically as a result of direct calculating perceived benefits against perceived risks (Dinev and Hart 2006, Awad and Krishnan 2006, Bansal and Gefen 2010). Specifically, perceived risks are negatively influence information disclosure while perceived benefits are positively impact information disclosure. Individuals are generally concerning the net value of benefits and costs, such that they expect the desired behaviors can bring higher benefits given the same costs or lower the overall costs given the same benefits (Adams 1963; Xu et al. 2011).

However, no research focuses on the issue of private information disclosure from hosts' perspective in accommodation sharing platforms contexts. The notion of privacy as a commodity has been established for more than two decades (Bennett 1995). Research has been done to understand why consumers are willing to provide their private information online in exchange for personalized service (Awad and Krishnan 2006). Although commodification of privacy is a measurable result of a real individual shift which is also subject to the economic principles of cost-benefit analysis and trade-off (Smith et al. 2011), there is a lack of research attention and formal theorizing on the commodification of privacy in accommodation sharing platforms. In this study, we propose the concept of information commercialization as individual's belief that private information of themselves and their listings can be commercialized to trade for profits or financial gains. We argue that information commercialization plays a vital role in triggering providers' information disclosure behaviors on accommodation sharing platforms.

Moreover, most privacy research focuses only on the individual level mechanisms while neglecting the potential interplays between individual perceptions and contextual factors (see Smith et al. 2011 for a review). A single-level study engenders a mismatch between theoretical development (e.g., institutional privacy insurance approaches as the higher-level contextual factor) and empirical measurement and testing which occur at the individual level (Xu, Dinev, Smith, and Hart 2008). Platforms have differentiated privacyenhancing features and mechanisms that provide users with confidence in appropriate access of their information (Xu et al. 2012). Not all the information a host released on the platforms is available for platform visitors to view directly. Some highly sensitive information like government ID and driver license is only verified by Airbnb, the platform business, while being invisible to consumers. Selected information such as specific home address is only accessible to consumers who have already been in a transaction with the given provider on the Airbnb platform. Prior literature suggests that such privacy-enhancing features and platform policies help mitigate privacy fears of participants (Smith et al. 2011). Therefore, there is a need for a cross-level study investigating how the predominant individual-level factors (such as privacy concern, perceived riskiness and benefit expectancy) and platform-level factors (i.e., design features and privacy policies) interplay to collectively impact personal information disclosure. 
Drawing on the privacy calculus theory and the literature of information-as-a-commodity perspective, this study aims to explore the impacts of hosts' privacy concerns, perceived riskiness and perceived ambiguity on their private information disclosure and the underlying mechanisms. This study will fill in the research gap by theorizing the concept of information commercialization in accommodation sharing platforms and addressing its formation mechanisms and behavioral outcome. Specifically, it aims to answer the question: What influence hosts to disclose their private information on the accommodation sharing platforms, and how?

From the hosts' perspective, our study proposes how (a) privacy concern, perceived riskiness, and perceived ambiguity, (b) economic benefit, platform privacy control factors jointly influence information commercialization, and (c) the role of information commercialization in hosts' information disclosure decision on accommodation sharing platforms. The rest of the paper is structured as follows. First, we review prior literature on information self-disclosure. Second, we draw from the privacy literature to propose the notion of information commercialization in accommodation sharing platforms context. Third, we elaborate six propositions that explain why hosts would possibly disclose private information on accommodation sharing platforms only when they believe in information commercialization. Forth, an empirical test plan is described. We conclude with a brief discussion.

\section{Theoretical Development 2.1. Information Self-disclosure and Its Explanatory Theories}

Privacy research has long studied why individuals are willing to disclose their personal information online. There are generally three streams of research within this broad area: one aiming at information privacy concern and its various antecedents, one focusing on risk-benefit analysis (e.g., privacy calculus theory, utility theory, etc.) to examine users' intention or willingness to disclose private information, and another drawing on theory of planned behavior and theory of reasoned action to understand users' intention and actual behavior. Table 1 summarizes the theories adopted in previous information privacy literature.

\subsection{Information Commercialization}

The concept of commercialization originates in the marketing field, referring to the process of managing or running something principally for financial gain, which
Table 1 Theories adopted in the information disclosure literature

\begin{tabular}{|c|c|c|}
\hline Theory & Description & $\begin{array}{l}\text { Example } \\
\text { Study }\end{array}$ \\
\hline $\begin{array}{l}\text { Privacy calculus } \\
\text { theory }\end{array}$ & $\begin{array}{l}\text { An individual's intention to } \\
\text { disclose private information } \\
\text { is based on risk-benefit } \\
\text { analysis. They compare } \\
\text { perceived risks and benefits } \\
\text { to make decision. }\end{array}$ & $\begin{array}{l}\text { Dinev and } \\
\text { Hart (2006) }\end{array}$ \\
\hline $\begin{array}{l}\text { Social exchange } \\
\text { theory }\end{array}$ & $\begin{array}{l}\text { Individuals actively conduct } \\
\text { subjective assessments to } \\
\text { compare the potential costs } \\
\text { and benefits of an activity } \\
\text { before engaging in it. }\end{array}$ & $\begin{array}{l}\text { Loiacono } \\
\text { (2015) }\end{array}$ \\
\hline $\begin{array}{l}\text { Social contract } \\
\text { theory }\end{array}$ & $\begin{array}{l}\text { An equitable exchange in a } \\
\text { long-term relationship should } \\
\text { be achieved by shared } \\
\text { understanding about } \\
\text { contractual terms and self- } \\
\text { control over the period of the } \\
\text { relationship. }\end{array}$ & $\begin{array}{l}\text { Li et al. } \\
\text { (2010) }\end{array}$ \\
\hline $\begin{array}{l}\text { Theory of planned } \\
\text { behavior }\end{array}$ & $\begin{array}{l}\text { Attitude towards behavior, } \\
\text { subjective norms, and } \\
\text { perceived behavioral control, } \\
\text { impact an individual's } \\
\text { behavioral intentions and } \\
\text { behaviors. }\end{array}$ & $\begin{array}{l}\text { Xu et al. } \\
\text { (2013) }\end{array}$ \\
\hline $\begin{array}{l}\text { Theory of reasoned } \\
\text { action }\end{array}$ & $\begin{array}{l}\text { Person's intention of } \\
\text { behavior is a primary } \\
\text { predictor to actual behavior. }\end{array}$ & $\begin{array}{l}\text { Taylor et al. } \\
\text { (2009) }\end{array}$ \\
\hline Utility theory & $\begin{array}{l}\text { People make decision by } \\
\text { maximizing their utility } \\
\text { function over alternatives. }\end{array}$ & $\begin{array}{l}\text { Bansal et } \\
\text { al. (2010) }\end{array}$ \\
\hline $\begin{array}{l}\text { Communication } \\
\text { privacy management } \\
\text { theory }\end{array}$ & $\begin{array}{l}\text { People believe they own and } \\
\text { have a right to control their } \\
\text { private information. An } \\
\text { individual's privacy } \\
\text { boundary governs his or her } \\
\text { self-disclosures. }\end{array}$ & $\begin{array}{l}\text { Petronio } \\
\text { (2013) }\end{array}$ \\
\hline Personality theory & $\begin{array}{l}\text { Personality traits, such as the } \\
\text { "Big Five" personality } \\
\text { model, can affect } \\
\text { individual's cognitive } \\
\text { processes and their } \\
\text { corresponding behaviors. }\end{array}$ & $\begin{array}{l}\text { Wang and } \\
\text { Stefanone } \\
\text { (2013) }\end{array}$ \\
\hline $\begin{array}{l}\text { Agency theory } \\
\text { (Principal-agency } \\
\text { theory) }\end{array}$ & $\begin{array}{l}\text { Goals of the principal and } \\
\text { agent conflict. Principal and } \\
\text { agent have different } \\
\text { preference towards risk. }\end{array}$ & $\begin{array}{l}\text { Pavlou et } \\
\text { al. (2007) }\end{array}$ \\
\hline
\end{tabular}

mainly focus on tangible assets (e.g. technology). Management research further suggests that intangible assets can also be commercialized to marketplace, including ideas (Gans and Stern 2003) and knowledge (Rasmussen et al. 2006). However, commercialization of information via the Internet is still in infant stage (Morin \& Konstantas, 2000) and there surprisingly 
lacks a formal conceptualization of information commercialization in the research on ubiquitous ecommerce activities that feature information-based transactions.

It is a common phenomenon in online business that an individual expresses strong privacy concerns but behaves in a contradictory way to these concerns (e.g., Acquisti and Grossklas 2005). One pervasive explanation of this paradox is commodification of privacy, which means consumers have reconceptualized privacy from a right or civil liberty to a commodity that can be exchanged for perceived benefits (Bennett 1995; Campbell and Carlson 2002). When treated as a commodity, individuals' private information can be assigned an economic value based on economic principles (i.e., cost-benefit calculation) at both individual level and societal level (Smith et al 2011; Pavlou 2011). In fact, consumers have been familiar with getting rewards (e.g., coupons or gifts) offered by companies when they release their personal information in order to register the membership or loyalty program of various businesses, offline or online.

\section{Table 2 Comparison between commercialization concepts}

\begin{tabular}{clll}
\hline Commerciali & $\begin{array}{l}\text { Information } \\
\text { Commerciali } \\
\text {-zation }\end{array}$ & $\begin{array}{l}\text { Information } \\
\text { Commerciali- } \\
\text { zation on } \\
\text { Airbnb platform }\end{array}$ \\
\hline Object & $\begin{array}{l}\text { Product or } \\
\text { production } \\
\text { method / } \\
\text { technology }\end{array}$ & $\begin{array}{l}\text { Digital } \\
\text { contents }\end{array}$ & $\begin{array}{l}\text { Personal } \\
\text { information such } \\
\text { as age, } \\
\text { education, } \\
\text { profession, } \\
\text { interests and } \\
\text { hobbies, photos } \\
\text { of interior design }\end{array}$ \\
& $\begin{array}{l}\text { Purpose } \\
\text { Make profit } \\
\text { or financial } \\
\text { gains }\end{array}$ & $\begin{array}{l}\text { Make profit } \\
\text { or financial } \\
\text { gains }\end{array}$ & $\begin{array}{l}\text { Increase } \\
\text { exposure among } \\
\text { platform visitors, } \\
\text { attracting their } \\
\text { attention }\end{array}$ \\
& & Online \\
Context & $\begin{array}{l}\text { Context- } \\
\text { independent }\end{array}$ & $\begin{array}{l}\text { Mostly } \\
\text { online }\end{array}$ & Ond \\
\hline
\end{tabular}

With the development of e-marketing and increasing business emphasis on consumer data gathering, online users are more and more used to providing their personal information for valuable resources on various websites. Therefore, it is theoretically necessary to develop the construct of information commercialization in a systematic way. In the accommodation sharing context, information exchange between consumers and hosts is not equitable, as consumers rarely reveal their personal information to hosts. It is this inequality in the relationship between consumers and hosts in the marketplace that compels hosts to provide personal information voluntarily, more than the necessary data mandated by the platform (Campbell and Carlson 2002). Consistent with privacy as commodity perspective (Campbell and Carlson 2002; Davies 1997; Smith et al. 2011), we define information commercialization in accommodation sharing context as individual hosts' belief that private information of themselves and their listings can be commercialized to trade for profits or financial gains. Table 2 compares the three constructs: commercialization, information commercialization, and information commercialization in the context of accommodation sharing platforms, such as Airbnb.

Hosts' participation in accommodation sharing does not require more information than absolutely necessary to complete accommodation sharing transactions (for example, basic property data such as property size, number of rooms, beds and bathrooms). Hosts who voluntarily publish more details than basic information are likely willing to treat their personal information as a kind of commodity in the belief that information of themselves and of their listings represent a reasonable transaction cost (Campbell and Carlson 2002); in other words, information could be commercialized in an exchange for economic benefits, even though the information does not have immediate financial relevance. Only when people hold a belief that their private information could be readily traded, like a commercial asset, they might choose to participatorily disclose more personal information online (Westin 2000). In contrast, if a host does not hold that private information can be commercialized, he or she is unlikely to release their information to public even though this focal individual is not privacysensitive. Therefore, we expect information commercialization will be a key antecedent that triggers hosts' information disclosure.

Proposition 1: Information commercialization positively impacts hosts' information disclosure on accommodation sharing platforms.

\subsection{Privacy Concern}

Privacy concern refers to the consumer's concern for controlling the acquisition and subsequent use of information that is generated or acquired in online transactions (Castañeda and Montoro 2007). A large number of studies have empirically examined the negative impact of consumers' privacy concern on consequence variables such as willingness to disclose information, engagement in e-commerce and actual purchase (Smith et al. 2011). Another stream of 
research studies the antecedent variables of individual consumer's privacy concern, including information characteristics (information type and information sensitivity), individual factors (demographics, personality and cognition) and social and cultural aspects (Malhotra et al. 2004; Phelps et al. 2000; Dinev et al. 2006).

Building upon the privacy calculus theory (PCT), a majority of privacy studies hold the view that individuals will calculate the benefits and risks before disclosing their private information (Culnan and Bies 2003; Dinev and Hart 2006; Dinev et al. 2006). When individuals believe that the overall benefit of information release exceeds perceived risk, they are more likely to disclose private information (Culnan and Bies 2003). However, we argue that individuals tend to not treat their personal data as a commodity if they really concern for controlling who might use their personal data and how they might use the data. If a host has a high degree of privacy concern, he or she is less likely to believe that private information is a commercial object which can be exchanged for benefits. Thus, we propose:

Proposition 2: Privacy concern negatively impacts hosts' information commercialization.

\subsection{Perceived Riskiness and Perceived Ambiguity}

Disclosing personal information online is risky for individuals because others may take the chance to conduct opportunistic behaviors (Malhotra et al. 2004). Perceived riskiness and perceived ambiguity are a pair of psychological constructs that negatively influence decision-making behavior (Venkatraman et al. 2006). Perceived riskiness means the threat of loss or harm while perceived ambiguity refers to the situations where the probability judgments an individual can bring to bear upon a particular problem are vague (Ellsberg 1961; Venkatraman et al. 2006). Being consistent with the prior literature (Venkatraman et al. 2006), we define perceived riskiness in the accommodation sharing context as hosts' anticipatory appraisal of their potential loss of disclosing private information on the sharing platforms.

On one hand, high level of perceived riskiness makes people consider the potential for losses and the significance of the losses (Yates and Stone 2002), which will reduce the likelihood for people to take the risk-bearing actions (Mahmoodi et al. 2018). In our research context, if hosts' perception of risk induced by the possibility of others' opportunistic behavior is high, they may not choose to commercialize their private information. On the other hand, perceived absence of relevant information or information vagueness will let people have less interest in a certain action (Fox and Weber 2002). The commodity sold on accommodation sharing platforms is hosts' private living space; there is no proprietary right transfer during transaction process or afterward. Compared to detailed description of listings, hosts know bare of information about consumers, except for self-reported number of residents. It would be difficult or impossible for hosts to form a good understanding of the overall probability of information abuse or other privacy-related risks. Moreover, hosts cannot correctly predict if releasing personal information on accommodation sharing platforms would bring future financial benefits as they expected. These perceived ambiguities likely function as an obstruction discouraging the hosts from considering private information as a commodity for economic exchange. This leads to the following propositions:

Proposition 3: Perceived riskiness negatively impacts hosts' information commercialization.

Proposition 4: Perceived ambiguity negatively impacts hosts' information commercialization.

\subsection{Moderating Effects of Economic Benefit}

One major reason of participation in sharing platforms is that providers can obtain reward or compensation by allocating their own resources through collaboration (Belk 2014; Hamari et al. 2016). Previous research suggests that consumers are willing to trade their private information for explicit and tangible benefits or rewards, such as allowing financial firms to collect credit card consumption information in exchange for extension of credit and filling up the questionnaire offered by businesses to get discount for next purchase (Laudon 1996). The privacy economics literature generally argues that the privacy decisionmaking process follows the rule of bounded rationality.

However, the influence of economic considerations and psychological influences could take effect on people's belief formation differently (Acquisti and Grossklags 2005). Specifically, the benefits of private information disclosure (for example, attracting more visitors' browsing, more orders, etc.) are expected, not immediately realized or guaranteed, but the risk of releasing such information might burst right after the disclosing behavior, is irreversible and may spread over time. Future events may be discounted compared to near-term events (Acquisti 2004). Hence, we believe that privacy concern, perceived riskiness and perceived ambiguity would not work in a manner same as benefit expectancy does. Hosts are likely willing to treat their personal information as a commodity for trading when 


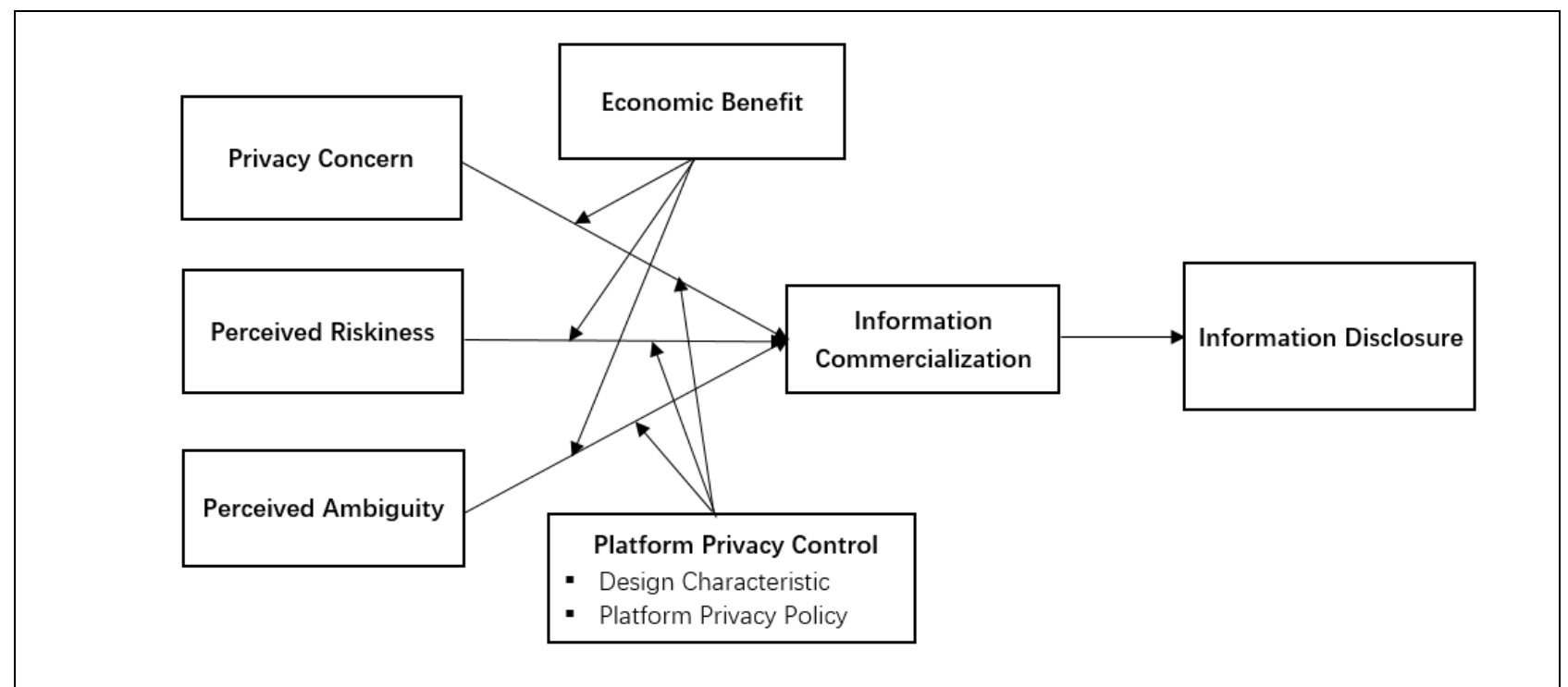

Figure 1. Theoretical framework

they have less concerns and low level of perceived riskiness and ambiguity. However, economic benefit would attenuate the negative impacts of these three antecedents of information commercialization. Thus,

Proposition 5: The negative impacts of (a) privacy concern, (b) perceived riskiness, and (c) perceived ambiguity on hosts' information commercialization are moderated by the expected economic benefit, such that the relationships will be weakened when economic benefit is expected to be high, not low.

\subsection{Moderating Effects of Platform Privacy Control}

Accommodation sharing platforms provide various control measures to protect the privacy. In Airbnb, hosts are required to provide a photo of a government ID which could be driver license, passport or alike. The private information contained in government ID such as date of birth, age and home address is only verified by and would be accessible to the platform business, rather than consumers. This design feature significantly decreases the negative impact of concerns for opportunistic use of the private information by malicious visitors or consumers on hosts' willingness to adopt a commodity view of their personal information.

Furthermore, hosts' contact information and home address are invisible to consumers unless they proceed to the transactional process. These platform characteristics could help protect hosts' private information and attenuate the negative effect of their privacy concern.
Privacy policies are written statements to explain the collecting and usage of participants' private information (Awad and Krishnan, 2006). Privacy policies can enhance people's trust on the platform thus they are more likely relieved of worries about participation in the platform-based transactions (Wu et al. 2012). Therefore, we expect that a high level of platform privacy control will weaken the negative effects of privacy concern, perceived riskiness and perceived ambiguity on hosts' information commercialization. Thus, we propose:

Proposition 6: The negative impacts of (a) privacy concern, (b) perceived riskiness, and (c) perceived ambiguity on hosts' information commercialization are moderated by the accommodation sharing platforms' privacy control, such that the relationships will be weakened when platform privacy control is strong, not weak.

Figure 1 depicts the theoretical framework.

\section{Methodological Plan}

The proposed research framework will be empirically tested using survey data. We mainly adopted the measurement instruments that have been validated in prior literature and made only minor adaptations in order to fit the accommodation sharing context of this research. Specifically, privacy concern will be measured using the scale of Internet users' information privacy concerns developed by Malhotra et al. (2004). Measures of perceived riskiness and perceived ambiguity are based on Venkatraman et al. (2006). Hamari et al. (2016)'s scale measuring 
economic benefit will be adapted to capture the benefit expectation of hosts. Platform privacy control will be measured by adopting the items by Taylor et al. (2009). Since the construct of information commercialization in accommodation sharing platforms is newly conceptualized, we will follow the procedures suggested by Moore and Benbasat (1991) to develop the measures.

The first draft of the questionnaire will be submitted to the IS scholars and privacy experts for review. The final version of questionnaire will be revised according to the opinions and suggestions of the review panel. We plan to pre-test the proposed survey questionnaire using a pilot sample of 150 Airbnb hosts. We will perform an Exploratory Factor Analysis (EFA) and Confirmatory Factor Analysis (CFA) to assess the validity of the self-developed measure for information commercialization.

We will then use the validated measures in the main study which will be conducted in a large sample of Airbnb hosts across the world. An online survey will be developed using the Qualtrics3 online survey platform provider and survey participants will be recruited on Amazon's Mechanical Turk (mTurk) platform.

\section{Discussions}

This study aims to explore the impact of individual service providers' information commercialization on sharing economy platforms, using Airbnb as an example, and examine the forming mechanisms of information commercialization. To this end, we firstly develop the concept of information commercialization from the hosts' perspective and argue that information commercialization plays a mediating role in converting hosts' psychological status (i.e., privacy concern, perceived riskiness and perceived ambiguity) to their private information disclosure on accommodation sharing platforms. Next, we explore the moderating effects of economic benefit and platform privacy control on the relationships between independent variables and hosts' information commercialization.

Although privacy issue has been studies in various contexts of e-commerce, social networking site and healthcare industry, researchers dominantly focus on the consumer while ignoring the service providers' perspective in sharing economy platforms. This research firstly enriches the privacy literature by extending the research focus to the service provider's perspective. We also contribute to the privacy research by conceptualizing information commercialization and highlighting its central position in triggering information self-disclosure on collaborative consumption platforms. This construct could serve as the foundation for future research on other types of sharing economy or e-commerce. Thirdly, we identify three antecedents of information commercialization, namely, privacy concern, perceived riskiness and perceived ambiguity, and consider the potential interactive effects of economic benefit and platform privacy control on information commercialization. We hope this study could provide an alternative insight into the complex process that impacts sharing economy participants' decision-making.

\section{References}

[1] Awad, N. F., \& Krishnan, M. S. (2006). The personalization privacy paradox: an empirical evaluation of information transparency and the willingness to be profiled online for personalization. MIS Quarterly, 13-28.

[2] Acquisti, A., \& Grossklags, J. (2005). Privacy and rationality in individual decision making. IEEE security \& privacy, 3(1), 26-33.

[3] Acquisti, A. (2004). Privacy in electronic commerce and the economics of immediate gratification. In Proceedings of the 5th ACM conference on Electronic commerce (pp. 21-29). ACM.

[4] Anderson, C. L., \& Agarwal, R. (2011). The digitization of healthcare: boundary risks, emotion, and consumer willingness to disclose personal health information. Information Systems Research, 22(3), 469-490.

[5] Adams, J. S. (1963). Towards an understanding of inequity. The Journal of Abnormal and Social Psychology, 67(5), 422.

[6] Breen, K. (2017). Toronto Airbnb host speaks out after $\$ 21,000$ theft. Retrieved from: https://globalnews.ca/news/3342635/toronto-airbnb-hostspeaks-out-after-21000-theft/

[7] Bansal, G., Zahedi F., \& Gefen, D. (2010). The impact of personal dispositions on information sensitivity, privacy concern and trust in disclosing health information online. Decision support systems, 49(2), 138-150.

[8] Bennett, C. J. (1995). The political economy of privacy: a review of the literature. Hackensack, NJ: Center for Social and Legal Research.

[9] Campbell, J. E., and Carlson, M. 2002. Panopticon.com: Online Surveillance and the Commodification of Privacy. Journal of Broadcasting\& Electronic Media (46:4), pp. 586606.

[10] Castañeda, J. A., \& Montoro, F. J. (2007). The effect of Internet general privacy concerns on customer behavior. Electronic Commerce Research, 7(2), 117-141. 
[11] Calo, R., \& Rosenblat, A. (2017). The taking economy: Uber, information, and power. Colum. L. Rev., 117, 1623.

[12] Culnan, M. J., \& Bies, R. J. (2003). Consumer privacy: Balancing economic and justice considerations. Journal of social issues, 59(2), 323-342.

[13] Davies, S. G. 1997. "Re-Engineering the Right to Privacy: How Privacy Has Been Transformed from a Right to a Commodity," in Technology and Privacy: The New Landscape, P. E. Agre and M. Rotenberg (eds.), Cambridge, MA: MIT Press, pp. 143-165.

[14] Dinev, T., \& Hart, P. (2006). An extended privacy calculus model for e-commerce transactions. Information systems research, 17(1), 61-80.

[15] Dinev, T., Bellotto, M., Hart, P., Russo, V., Serra, I., \& Colautti, C. (2006). Privacy calculus model in e-commerce-a study of Italy and the United States. European Journal of Information Systems, 15(4), 389-402.

[16] EMarketer. (2017). US Adult Sharing Economy Users and Penetration. Retrieved from https://www.emarketer.com/Chart/US-Adult-SharingEconomy-Users-Penetration-2016-2021-millions-of-adultinternet-users/209547

[17] Ellsberg, D. (1961). Risk, ambiguity, and the Savage axioms. The quarterly journal of economics, 643-669.

[18] Fox, C. R., \& Weber, M. (2002). Ambiguity aversion, comparative ignorance, and decision context. Organizational Behavior and Human Decision Processes, 88(1), 476-498.

[19] Gans, J. S., \& Stern, S. (2003). The product market and the market for "ideas": commercialization strategies for technology entrepreneurs. Research policy, 32(2), 333-350.

[20] Hamari, J., Sjöklint, M., \& Ukkonen, A. (2016). The sharing economy: Why people participate in collaborative consumption. Journal of the association for information science and technology, 67(9), 2047-2059.

[21] Jourard, S. M., \& Lasakow, P. (1958). Some factors in self-disclosure. The Journal of Abnormal and Social Psychology, 56(1), 91.

[22] Krasnova, H., Spiekermann, S., Koroleva, K., \& Hildebrand, T. (2010). Online social networks: Why we disclose. Journal of Information Technology, 25(2), 109-125.

[23] Li, H., Sarathy, R., \& Xu, H. (2010). Understanding situational online information disclosure as a privacy calculus. Journal of Computer Information Systems, 51(1), 62-71.

[24] Loiacono, E. T. (2015). Self-disclosure behavior on social networking web sites. International Journal of Electronic Commerce, 19(2), 66-94.
[25] Laudon, K. C. (1996). Markets and privacy. Communications of the ACM, 39(9), 92-104.

[26] Lutz, C., Hoffmann, C. P., Bucher, E., \& Fieseler, C. (2018). The role of privacy concerns in the sharing economy. Information, Communication \& Society, 21(10), 1472-1492.

[27] Malhotra, N. K., Kim, S. S., \& Agarwal, J. (2004). Internet users' information privacy concerns (IUIPC): The construct, the scale, and a causal model. Information systems research, 15(4), 336-355.

[28] Mahmoodi, J., Čurdová, J., Henking, C., Kunz, M., Matić, K., Mohr, P., \& Vovko, M. (2018). Internet users' valuation of enhanced data protection on social media: Which aspects of privacy are worth the most? Frontiers in psychology, 9, 1516.

[29]Morin, J. H., \& Konstantas, D. (2000). Commercialization of electronic information. Journal of Organizational and End User Computing (JOEUC), 12(2), 20-31.

[30] Pavlou, P. A. (2011). State of the information privacy literature: Where are we now and where should we go?. MIS quarterly, 977-988.

[31] Pavlou, P. A., Liang, H., \& Xue, Y. (2007). Understanding and mitigating uncertainty in online exchange relationships: A principal-agent perspective. MIS quarterly, 105-136.

[32] Petronio, S. (2012). Boundaries of privacy: Dialectics of disclosure. SUNY Press.

[33] Phelps, J., Nowak, G., \& Ferrell, E. (2000). Privacy concerns and consumer willingness to provide personal information. Journal of Public Policy \& Marketing, 19(1), $27-41$.

[34] Rasmussen, E., Moen, Ø., \& Gulbrandsen, M. (2006). Initiatives to promote commercialization of university knowledge. Technovation, 26(4), 518-533.

[35] Smith, H. J., Dinev, T., \& Xu, H. (2011). Information privacy research: an interdisciplinary review. MIS quarterly, 35(4), 989-1016.

[36] Strapagiel, L. (2018). This Woman's Experience as An Airbnb Host Turned Into A Complete Nightmare. BuzzFeed News, Retrieved from

https://www.buzzfeednews.com/article/laurenstrapagiel/airbn b-nightmare-harassment-arrest

[37] Taylor, D. G., Davis, D. F., \& Jillapalli, R. (2009). Privacy concern and online personalization: The moderating effects of information control and compensation. Electronic commerce research, 9(3), 203-223.

[38] Venkatraman, S., Aloysius, J. A., \& Davis, F. D. (2006). Multiple prospect framing and decision 
behavior: the mediational roles of perceived riskiness and perceived ambiguity. Organizational Behavior and Human Decision Processes, 101(1), 59-73.

[39] Wang, S. S., \& Stefanone, M. A. (2013). Showing off? Human mobility and the interplay of traits, self-disclosure, and Facebook check-ins. Social Science Computer Review, 31(4), 437-457.

[40] Westin, A. (2000). Intrusions: Privacy tradeoffs in a free society. Public Perspective, 11(6), 8-11.
[41] Wu, K. W., Huang, S. Y., Yen, D. C., \& Popova, I. (2012). The effect of online privacy policy on consumer privacy concern and trust. Computers in human behavior, 28(3), 889-897.

[42] Xu, H., Dinev, T., Smith, H. J., \& Hart, P. (2008). Examining the formation of individual's privacy concerns: Toward an integrative view. ICIS 2008 proceedings, 6 .

[43] Xu, H., Luo, X. R., Carroll, J. M., \& Rosson, M. B. (2011). The personalization privacy paradox: An exploratory study of decision-making process for location-aware 